\title{
Inductive method for the orientation of steel fibers in recycled mortars
}

\author{
D. Ferrández ${ }^{a}$, P. Saiz ${ }^{b}$, C. Morón ${ }^{\mathrm{a}, *}$, M.G. Dorado ${ }^{\mathrm{c}}$, A. Morón ${ }^{\mathrm{a}}$ \\ ${ }^{a}$ Departamento de Tecnología de la Edificación, Universidad Politécnica de Madrid, Madrid 28040, Spain \\ b Departamento de Economía Financiera, Contabilidad e Idioma Moderno, Universidad Rey Juan Carlos, Madrid 28032, Spain \\ ${ }^{c}$ Departamento de Educación, Universidad Camilo José Cela, Spain
}

\section{H I G H L I G H T S}

- It's possible the complete substitution of natural by recycled aggregates in mortars.

- Addition of orientated fibers improves the mechanical properties of cement mortars.

- A magnetic system has been developed to orientate steel fibers in cement mortars.

- It's possible to qualify magnetically the quantity of fibers orientates in mortars.

\begin{abstract}
A B S T R A C T
Mortars elaborated with recycled aggregates raise two main difficulties: lower mechanical strengths and higher shrinkage compared to traditional mortars. For this reason, fibers were used to improve the properties. Steel fibers are the most employed for their ferromagnetic qualities, what helps to orient them influenced by magnetic field. This paper argues how recycled mortars with steel fiber oriented under the influence of $500 \mathrm{mT}$ field reach flexural strengths $10 \%$ higher than those with non-oriented fibers. Thus, mechanical strengths are closer to traditional mortars. Inclusion of fibers in mortar is suitable for obtaining shrinkage values similar to those obtained in traditional mortars.
\end{abstract}

\section{Introduction}

Within the construction sector, the aging of buildings is problematic. Therefore, further studies that enable enhancing the properties of building materials are needed. This will allow their use in the refurbishing and restoration of buildings. In Spain, almost $2 \%$ of buildings are in a dilapidated condition and $7.6 \%$ are in poor condition. That means that there are more than 963,300 buildings that should undertake works of integral restoration $[1,2]$.

Apart from that, the massive exploitation of natural resources in the construction sector has grown steadily in the last decades. This fact has facilitated the development of new environmental policies that intend to favor the use of new materials with a lower environmental impact [3]. In this context, the construction and demolition waste (CDW) produced throughout the life-cycle of the building is growing in strength as a possible alternative to the use of the traditional building materials. The recycled aggregates (RA) are being

\footnotetext{
* Corresponding author at: Avda. Juan de Herrera, 6, 28040 Madrid, Spain. E-mail addresses: pablo.saiz@urjc.es (P. Saiz), carlos.moron@upm.es (C. Morôn).
}

one of the most employed components in the construction of new buildings $[4,5]$.

The cement mortars remain the most employed binder when executing works in the masonry factories that are built nowadays [6]. It is for this reason that research has been undertaken by replacing totally or partially the natural aggregate, traditionally employed, with another kind of RA. Despite the fact that these recycled aggregates contain impurities such as ceramic materials or gypsum whose content depends on the shredding process, they have provided good results in building applications $[7,8]$. When referring to aggregates and according to the current EHE-08 [9], the use of recycled concrete aggregate is regulated and limited to the $20 \%$ of replacement by natural aggregates (NA). In the case of masonry mortars, there is no limit of replacement. On the other hand, the majority of these studies has been performed on laboratory samples. However, it is true that some authors studies the influence of the size of the sample, opening new ways of investigation and reconsidering the suitability of the tests [10].

One of the main drawbacks of mortars elaborated with RA is that, on the one hand, they have a higher capacity to absorb mixing water and, on the other, they have lower densities than traditional 
mortars [11]. This higher absorption has a direct impact on the initial dosage and this, in turn, has a negative influence as the final mechanical strengths of the mortar lessen. This is due to the higher porosity of these materials [12]. Furthermore, the loss of volume is also more evident comparing to traditional mortars. This is why the recycled mortars show larger shrinkage [13] due to two different things. On the one hand, it can be caused by temperature due to exothermic reaction produced in the hydration of the anhydrous compounds of the cement [14]. On the other hand, it can also be caused by the drying produced when free water that remains stored in capillary pores evaporates due to low levels of relative environmental humidity [15].

Some authors have tried to improve mortars tenacity by incorporating fibers of small length and section in their matrix [16]. These fibers can have diverse origins: carbon, glass, basalt, etc. $[17,18]$, and their inclusion aims to better the mechanical properties of mortars without fiber [19]. The strength to crack propagation increases and the capacity to absorb energy and deformation capacity also improve [20]. Moreover, the harmful effects produced by shrinkage can be also reduced through the control of curing temperatures and the employment of fibers during mixing [21].

Research has been made in order to know the main causes of fibers orientation within the mortar matrix [22]: flow, vibration, type of mortar, casting method, fresh-state properties and formwork geometry. This way of fiber orientation can be conducted by vibration of specimens which will enable to reach orientation percentages close to $60 \%$. This will ameliorate the strength in the specimen in transversal direction to the applied stress [23]. In order to carry out this study, steel fiber has been incorporated because of its ferromagnetic materials. It will let us know the percentage of fibers oriented in all three spatial directions through inductive sensors [24]. Furthermore, a magnetic field generated by a powerful solenoid will be used. Thanks to this, fibers might be aligned in the direction of the coil axis so they will coincide with the longitudinal direction of the specimen. This will improve their flexural strength [25]. Some authors performed multidirectional double perforation tests (MDPT) in concrete samples in order to estimate the efficiency in fibres orientation, the method that presents a great scientific interest for developing concrete structures on the real scale [26].

The objective of this study is to design a system that is capable of orienting steel fibers in a fresh mortar with the aim of improving the mechanical properties of recycled mortars. In order to do that, a system able to generate a magnetic field in the longitudinal direction of the specimen has been implemented. It will also enable to orient fibers so that they will be parallel to the direction of the applied stress which will increase the final strength. Subsequently, thanks to an inductive detection system, it will be possible to quantify the fibers oriented in the chosen direction and to study the improvement of this orientation in the flexural strength and in the shrinkage of mortars specimens. The kind of RA chosen for this study comes from recycled concrete waste due to two different aspects; first, their higher strength in comparison with the ceramic and mixed aggregate; second, it tries to reach lower water absorption.

\section{Materials and methodology}

\subsection{Materials and dosages}

In order to elaborate mortar specimens, the following materials have been used: cement, natural aggregate, recycled concrete aggregate, steel fibers, water and additive.

\subsubsection{Cement}

The cement that has been used is CEM II $\mathrm{B} / \mathrm{L}-32,5 \mathrm{~N}$ because it is the most employed in masonry. The Spanish and European regulation UNE-EN 197-1: 2011 [27] and the instruction for the receipt of cements $\mathrm{RC}-08$ [28] specify properties of this kind of cements. Their main characteristics and chemical composition are shown in Table 1.

\subsubsection{Aggregates}

Specimens have been elaborated with natural aggregates (NA). The recycled concrete sands have been provided by the Construction and Demolition Wastes Treatment Plant TEC-REC. Due to the worse properties presented by the fine fraction in RA, samples collected were sieved in the laboratory in order to eliminate the remained fine fraction. The RA size has been $0 / 4 \mathrm{~mm}$ (material passing through the $4 \mathrm{~mm}$ sieve and retained in the $0.063 \mathrm{~mm}$ sieve). Fig. 1 plots the size distribution curve of recycled concrete aggregate.

\subsubsection{Steel fibers}

In order to elaborate reinforced mortars, smooth steel fibers with reduced thickness have been used. The aim of using them is to achieve a homogeneous and isotropic distribution after having oriented them. It will also enable to improve mechanical properties and shrinkage in recycled mortars. The quantity of fibers in each mix was calculated according to the volume of the aggregate $(0.5 \%$ and $1 \%$ ). Table 2 summarizes the main characteristics of these fibers.

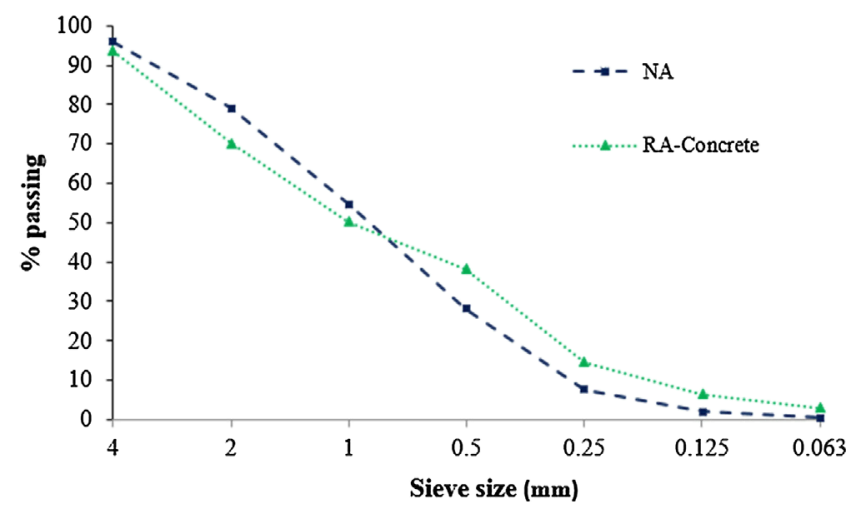

Fig. 1. Size distribution curve of aggregates.

Table 1

Characteristics of CEM II B/L $-32,5 \mathrm{~N}$.

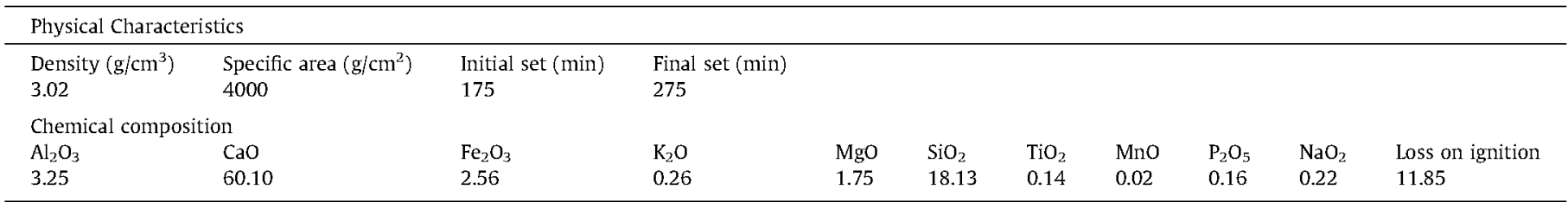


Table 2

Fibers characteristics.

\begin{tabular}{|c|c|c|c|c|c|}
\hline Fiber type & Length (mm) & Diameter (mm) & Elasticity module (GPa) & Tensile Strength (MPa) & Density $\left(\mathrm{g} / \mathrm{cm}^{3}\right)$ \\
\hline Steel & 22 & 0.5 & 200 & 1100 & 7.8 \\
\hline
\end{tabular}

\subsubsection{Water}

Water employed is innocuous, that is, it does not contain any agent in high quantities so that it could alter final properties of the mortar. To that end, the mixing water has been obtained directly from the tap, safe water of the Community of Madrid according to the requirements of the EHE-08. Table 3 displays the characteristics provided by the Canal de Isabel II.

\subsubsection{Mortar mixes elaboration}

The mortars that contain recycled concrete aggregate have been elaborated using superplasticizer additive Glenium Sky 604 by BASF company as recommended by its technical department to improve RA mortars consistency. This additive is a high range water reducer and superplasticizer based on polycarboxylate.

On the other hand, the description of the mortars used in these tests has the following coding:

$N-D-S F-\%$

where $N$ indicates aggregate type, that could be NA for natural aggregate and RA for recycled concrete aggregate, $D$ shows relation between cement and sand by weight proportion, letter $X$ describes relation between components $1: 3$ and letter $Y$ describes relation between components 1:4, SF refers to steel fiber and \% shows the fiber percentage added to the mortar mix according to Table 4 .

The preparation of all mixes has been developed using the same technique and equipment, following the standard UNE-EN 196-1 [29]. Specimens elaborated with recycled concrete aggregate were prepared using $1 \%$ of additive over the weight of the cement, complying with the limits established by the manufacturer. Final dosage can be seen in Table 4 . Water content of these specimens was experimentally set in order to achieve mixing with a consistency similar to the plastic one $(175 \pm 10 \mathrm{~mm})$, according to the standard UNE-EN 1015-2:1998 [30].

\subsection{Foundations of magnetism in steel fibers}

As it has been explained, the orientation of fibers in mortars can be considered a desired phenomenon as long as the piece works in only one direction. This means that steel fibers work in the mortar matrix strengthening substantially the piece. In order to orient a big amount of fibers, it is necessary to work with flowable or fluid consistency mortars. In this way, metallic fibers will be oriented under the effect of a magnetic field of a consistent and sufficiently high level.

For this reason, applying magnetic fields in shorter lengths is needed. Big coils are built although they have as disadvantage the need of high voltages and high manufacturing costs. In order to avoid these disadvantages, it could be used a coil designed for the specimen dimensions. To do so, the Biot-Savart law that relates the generation of a resultant magnetic field with a current distribution is applied. Thus, the field created by a current can be expressed differentially with the following Eq. (1):

$d \vec{B}=\frac{\mu_{0}}{4 \pi} \cdot \frac{I d \vec{l} \times \vec{r}}{r^{2}}$

where $\mu_{0} \mathrm{~s}$ the magnetic permeability, $I \mathrm{~s}$ the intensity of the current, $s$ the distance from the load to the observation point in the field and $B$ is the created magnetic field.

The following equations could be obtained by integrating the equation for a finite straight wire as the one presented in Fig. 2 [31]:

$$
H_{X}=0
$$

$$
\begin{aligned}
H_{Y}= & -\frac{z I}{4 \pi} \cdot \int_{b}^{b} \frac{d x}{\left[\sqrt{\left(x-x_{0}\right)^{2}+(y-a)^{2}+z^{2}}\right]^{3}}=-\frac{z I}{4 \pi\left[(a-y)^{2}+z^{2}\right]} \\
& \times\left[\frac{b-x}{\sqrt{(b-x)^{2}+(a-y)^{2}+z^{2}}}+\frac{b+x}{\sqrt{(b+x)^{2}+(a-y)^{2}+z^{2}}}\right]
\end{aligned}
$$

$$
\begin{aligned}
H_{Z}= & \frac{(y-a) I}{4 \pi} \cdot \int_{b}^{b} \frac{d x}{\left[\sqrt{\left(x-x_{0}\right)^{2}+(y-a)^{2}+z^{2}}\right]^{3}}=-\frac{(a-y) I}{4 \pi\left[(a-y)^{2}+z^{2}\right]} \\
& \times\left[\frac{b-x}{\sqrt{(b-x)^{2}+(a-y)^{2}+z^{2}}}+\frac{b+x}{\sqrt{(b+x)^{2}+(a-y)^{2}+z^{2}}}\right]
\end{aligned}
$$

Table 3

\begin{tabular}{|c|c|c|c|c|c|}
\hline Mix type & Cement/Aggregate ratio & Cement $(\mathrm{g})$ & Aggregate (g) & Water (g) & Steel fiber (\%) \\
\hline \multirow[t]{2}{*}{$N A$} & $1: 3$ & 450 & 1350 & 247.5 & - \\
\hline & $1: 4$ & 337.5 & 1350 & 209.3 & - \\
\hline \multirow[t]{2}{*}{$R A^{(1)}$} & $1: 3$ & 450 & 1350 & 306 & - \\
\hline & $1: 4$ & 337.5 & 1350 & 300.4 & - \\
\hline \multirow[t]{2}{*}{$R A-S F-0.5 \%$} & $1: 3$ & 450 & 1350 & 306 & 0.5 \\
\hline & $1: 4$ & 337.5 & 1350 & 300.4 & 0.5 \\
\hline \multirow[t]{2}{*}{$R A-S F-1 \%$} & $1: 3$ & 450 & 1350 & 306 & 1 \\
\hline & $1: 4$ & 337.5 & 1350 & 300.4 & 1 \\
\hline
\end{tabular}

Analysis of water employed for mixing.

\begin{tabular}{lllllllll}
\hline Color $(\mathrm{mg} / \mathrm{l})$ & $\mathrm{pH}$ & Turbidity $(\mathrm{UNF})$ & Conductivity $(\mu \mathrm{S} / \mathrm{cm})$ & Nitrate $(\mathrm{mg} / \mathrm{l})$ & Free chlorine $(\mathrm{mg} / \mathrm{l})$ & Chloride $(\mathrm{mg} / \mathrm{l})$ & Sulfide $(\mathrm{mg} / \mathrm{l})$ & Total Hardness $\left({ }^{\circ} \mathrm{F}\right)$ \\
\hline$<1,0$ & 7,9 & 0,1 & 108,6 & 0,6 & 0,5 & 3,7 & 5,3 & 4,8 \\
\hline
\end{tabular}

Table 4

Dosages in mortar mixes elaboration.

(1) All specimens elaborated with recycled aggregates contain $1 \%$ of additive over the weight of cement. 


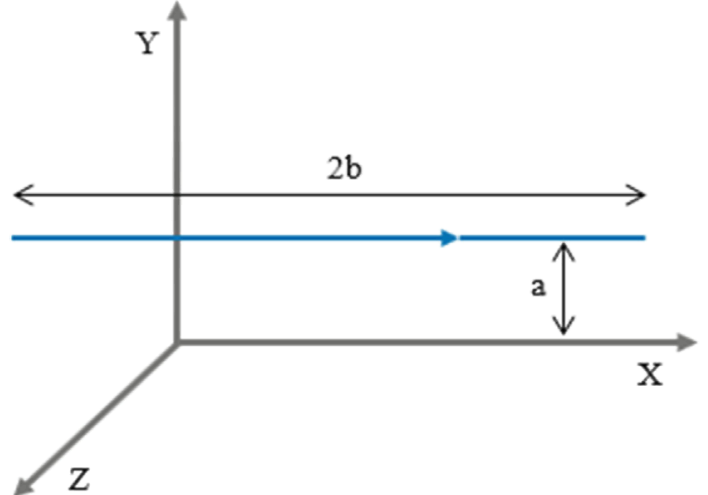

Fig. 2. Finite straight wire.

where $(x, y, z)$ are the Cartesians coordinates of the point where the magnetic field is calculated. From this equation, it can be obtained a magnetic field generated by a current with any geometry, just by adding the contribution of all corresponding turns.

In order to ensure that the theoretical calculation is adequate, several solenoids have been implemented. The conclusion reached is that in order to obtain a uniform magnetic field with dispersion lower than $1 \%$, it is necessary to build it with a length superior to the desired uniform region. The coil must not have a number of turns by constant length as the number of turns will be increased at the ends. Thus, a coil is made with $20 \mathrm{~cm}$ length and 8800 turns. The magnetic field obtained has been quite uniform, $12,5 \mathrm{~cm}$ in the main part of the coil.

As it can be seen in Fig. 3, the size distribution curve correlates well with the curve obtained theoretically. In this way and since the mortar should have just been mixed and it will be still fresh, the ferromagnetic fibers could be oriented in the direction of the solenoid axis by applying a magnetic field in specimens.

\subsection{Equipment implemented for the fibers orientation in mortars}

As shown in Fig. 4, in order to generate a magnetic field capable of orienting steel fibers in mortars, an electric circuit has been implemented. This circuit has enabled to quantify the intensity of the generated field, with the help of a Teslameter.

The magnetic field is accomplished through a primary coal fed by a function generator and a signal amplifier. In this way, the generated magnetic field inside the solenoid will be proportional to the intensity circulating through it. This intensity might be better measured through the fall of potential produced when passing by

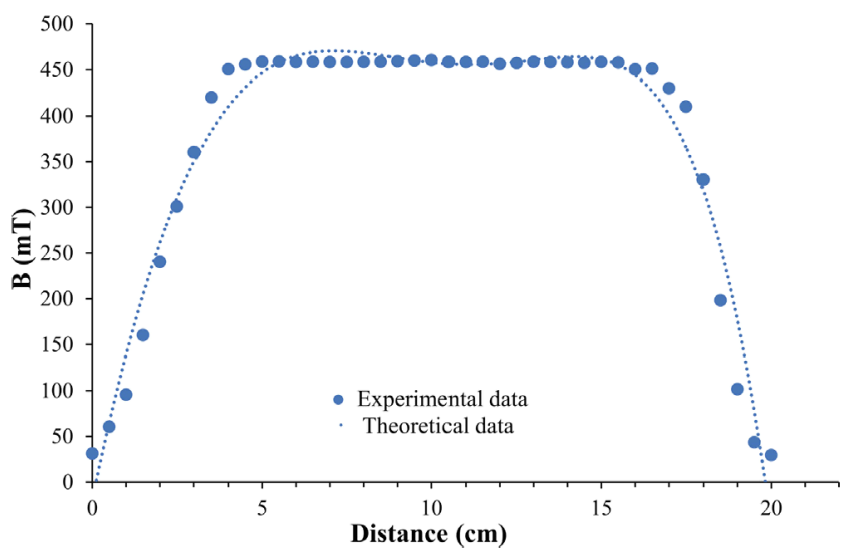

Fig. 3. Adjustment between the theoretical magnetic field and the one obtained experimentally with the implemented coil.

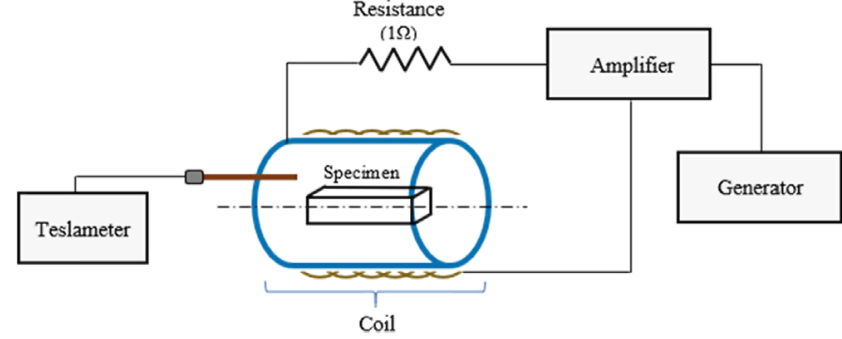

Fig. 4. Equipment diagram for the generation and quantification of the magnetic field.

a $1 \Omega$ pattern resistance connected in series with the primary circuit.

As has been argued above, the magnetic field generated by the solenoid is a maximum in the coil center and it gets reduced as it approaches the ends. This effect is beneficial for the metallic fibers orientation in mortars as this orientation will be higher in the bottom area of the central part in the specimen. This part is under much strength when the flexural test is tested (Fig. 5). This is one of the less successful mechanical characteristics in recycled mortars and it is intended to be improved with the inclusion of fibers.

The flexural strength $\sigma_{f}$ is represented by the ratio between the bending moment $\left(M_{f}\right)$ and the moment resisting $(W)$, according to the equation

$\sigma_{f}=\frac{M_{f}}{W}=\frac{\frac{P \cdot l}{4}}{\frac{a \cdot b^{2}}{6}}=\frac{3 \cdot P \cdot l}{4 \cdot a \cdot b^{2}}$.

where $P$ is the applied load, ${ }_{l}$ is the distance between two supports, $a$ is the width of the specimen and $b$ is the tip of the specimen.

\subsection{Content quantification and fibers orientation}

Due to the mortar consistency in liquid form and due to the limitation of the field intensity (around $450 \mathrm{mT}$ ), it is not possible to orient all the fibers introduced in the mortar matrix. In order to obtain the amount of oriented steel fibers, the inductive method has been used [32]. A coil, shown in Fig. 6 and with $30 \mathrm{~cm}$ length, $8 \mathrm{~cm}$ diameter and 1567 turns, has been built. The characteristic parameter of this coil is the coefficient of self-induction as it only depends on geometrical factors such as length, diameter and the thickness of the turns' layers.

In this way, the method of measurement has been gaged measuring the variation of the coefficient of self-induction with the amount of fibers included in the solenoid. The coefficient of selfinduction has been measured with the self-induction measuring device MZ-505 and the impedance analyzer Agilent 4395A to $120 \mathrm{~Hz}$. Taking into account that the mortar is a non-magnetic material, the only variation of the coefficient of self-induction would be due to the amount of steel fibers introduced. In Fig. 7, it can be observed that the variation of the coefficient of selfinduction is linear with the fibers content.

The verification of the actual content in fibers and the calibration of the inductive method for the type of fiber employed has been done hammering the specimens and measuring the weight of fibers according to the standards UNE-EN 14721:2006 $+\mathrm{A} 1: 2008$ [33].

\subsection{Experimental study}

The experimental program has been divided in three welldifferentiated phases according to the tests conducted and the classification of the findings achieved. 


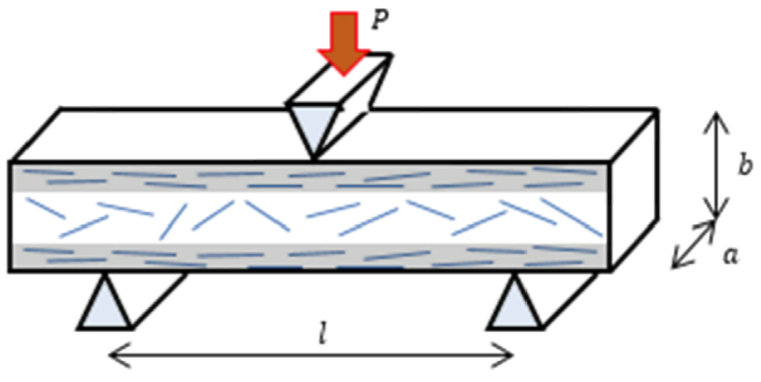

(a)

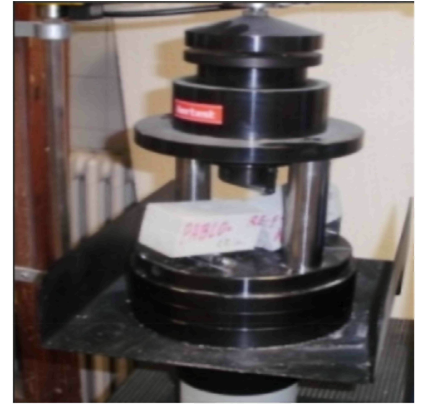

(b)

Fig. 5. (a) Diagram of metallic fiber oriented in the mortar specimen; (b) Flexural strength test according to the standards UNE-EN 1015 -11.

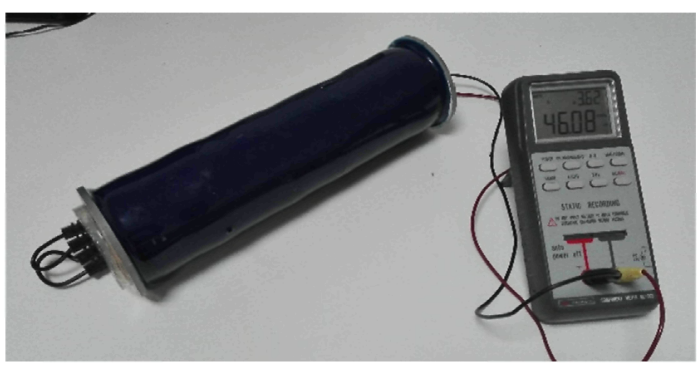

Fig. 6. Coil to quantify the orientation and quantity of fibers by an inductive method.

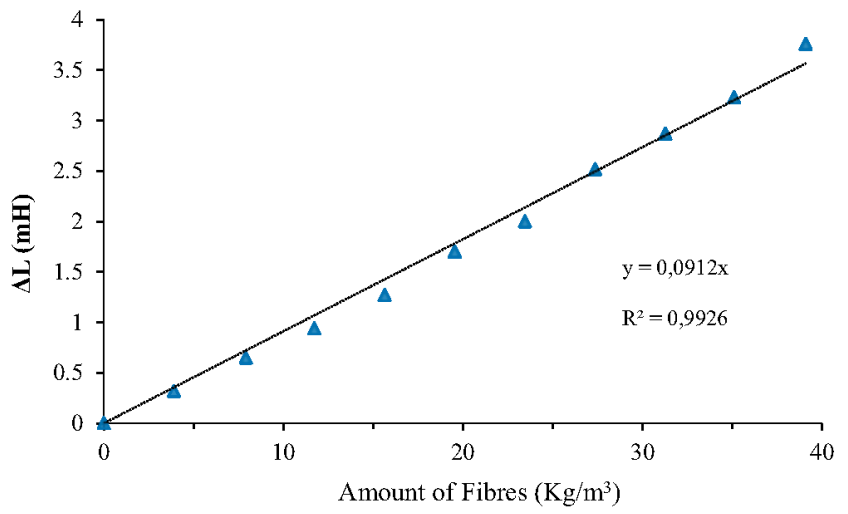

Fig. 7. Correlation between fibers content and the self-induction measured with the solenoid.

In the first phase, the main characteristics of recycled concrete aggregates were studied. In order to do that, a physicochemical characterization of them was carried out through the most representative tests proposed by the standard UNE which regulates the characterization of aggregates for masonry mortars. Subsequently, the study was completed with X-ray fluorescence and Xray diffraction methods.

In a second phase, recycled and reference mortars were elaborated. Steel fibers were included during mixing and were oriented with a solenoid designed for that particular purpose. The mortar was hardened and cured in the curing chamber for 28 days under $95 \%$ humidity and $20^{\circ} \mathrm{C}$ temperature. After that, the content of fibers was quantified as well as their orientation inside the specimens mixed with $0.5 \%$ steel fiber weight and with $1 \%$ steel fiber weight.

Finally, mechanical testing has been conducted in order to know better the characteristics of the elaborated material. In order to do that, standardized specimens RILEM with dimensions $40 \times 40 \times 160 \mathrm{~mm}$ have been used. After being cured in a humid chamber, their bulk and real density as well as their compacity were studied. Subsequently, flexural and compressive tests were conducted following the guidelines of the standard UNE-EN 1015-11:1999 [34] which regulates flexural and compressive tests on mortars.

In addition, shrinkage measuring was also carried out with a manual comparator that measured the variation in the specimens lengths during each drying phase, since they have been unmoulded following the standard UNE 80-112-89 [35], and measuring in specimens with dimensions $25 \times 25 \times 287 \mathrm{~mm}$. Therefore, shrinkage is expressed as a percentage $\Delta L_{n d}(\%)$ respect to the initial length given by the following Eq. (6):

$\Delta L_{n d}=\frac{M_{n d}-M_{1 d}}{L_{0}} 100[\%]$.

where $L_{0}$ is the inner length of the mould, $M_{n d}$ is the comparator measure after $\mathbf{n}$ days and $M_{1 d}$ is the comparator measure on the first day.

The shrinkage measurement period was 180 days since the specimen had been removed from its mould till the last measurement. These measures enable to quantify the beneficial effect of the inclusion of fibers in the matrix of the recycled mortars and also to study the feasibility of the fibers orientation with the aim of improving their strengths and their final shrinkage.

\section{Results and discussion}

\subsection{Recycled concrete aggregates characterization}

Recycled concrete aggregates characterization was accomplished following the standard UNE-EN 13139:2002 [36]. The results of physical and chemical characteristics for both recycled concrete aggregates (RCA) and natural aggregates (NA) are listed in Table $5[37-40]$.

As it can be seen in Table 5, the density of recycled concrete aggregate (RCA) is lower than the natural aggregate (NA) density whereas water absorption values of the RA are much higher than the values obtained by NA (as set out in the consulted literature). This high water absorption is the main reason to have recycled mortars with a higher shrinkage. However, the values of absorption reached are below the recommended for this kind of materials [41].

The obtained results of X-ray fluorescence method for the recycled concrete aggregate are shown in Table 6.

Results in Table 6 indicate that, for RA, there is a high level of silicates $\mathrm{SiO}_{2}$ (68.2\%), followed by a high percentage of $\mathrm{Al}_{2} \mathrm{O}_{3}$ and $\mathrm{CaO}$. Besides that, SO3 content $(0.338 \%)$ does not exceed the limit 
Table 5

Characterization of the aggregates.

\begin{tabular}{|c|c|c|c|c|c|c|c|}
\hline Test & Fine Content $(\%)$ & Particle Form & Fineness modulus (\%) & Friability (\%) & Bulk. dens, $\left(\mathrm{Kg} / \mathrm{m}^{3}\right)$ & Dry dens. $\left(\mathrm{Kg} / \mathrm{m}^{3}\right)$ & Water Absortion (\%) \\
\hline Standard & UNE EN 933-1 & UNE-EN 13139 & UNE-EN 13139 & UNE-EN 83115 & UNE-EN 1097-3 & UNE-EN 1097-6 & UNE-EN 1097-6 \\
\hline $\mathrm{RCA}$ & 3.97 & Not relevant & 4.28 & 24.12 & 1310 & 2100 & 6.01 \\
\hline NA & 2.58 & - & 4.25 & 22.63 & 1560 & 2450 & 0.95 \\
\hline
\end{tabular}

Table 6

$\mathrm{X}$-ray fluorescence.

\begin{tabular}{|c|c|c|c|c|c|c|c|c|c|c|c|c|}
\hline Aggr. & $\mathrm{Al}_{2} \mathrm{O}_{3}$ & $\mathrm{CaO}$ & $\mathrm{Fe}_{2} \mathrm{O}_{3}$ & $\mathrm{~K}_{2} \mathrm{O}$ & $\mathrm{MgO}$ & $\mathrm{SiO}_{2}$ & Mno & $\mathrm{TiO}_{2}$ & $\mathrm{SO}_{3}$ & $\mathrm{P}_{2} \mathrm{O}_{5}$ & $\mathrm{Na}_{2} \mathrm{O}$ & I.Loss (\%) \\
\hline $\mathrm{RCA}$ & 6.98 & 10.67 & 1.22 & 2.16 & 0.54 & 68.2 & 0.022 & 0.15 & 0.338 & 0.1 & 0.22 & 9.4 \\
\hline
\end{tabular}

of $1 \%$ established by the standard UNE-EN 13139:2002 for the aggregates used in mortar fabrication as higher levels of this chemical damage the mechanical characteristics of the elaborated mortars reducing significantly their durability.

The crystalline structures and the purity of specimens were analyzed by X-ray diffraction (XDR). The X-ray diffraction pattern was measured using a $\mathrm{Cu}-\mathrm{K} \alpha$ radiation $(\lambda=1.540598 \AA)$ by a diffractometer equipped with a monochromator of graphite. Data were collected at $300 \mathrm{~K}$ in steps of $0.05^{\circ}$ measured in a range of $10^{\circ} \leq 2 \theta \leq 110^{\circ}$ taken every $10 \mathrm{~s}$ with a current of $20 \mathrm{~mA}$ and a $40 \mathrm{kV}$ voltage.

As it can be seen in Table 7 , the main crystalline phases obtained with the X-ray diffraction method are quartz and calcite. The number of stars is used to quantify the relative abundance of each crystalline phase in analysed samples.

\subsection{Orientation and fibers distribution}

Firstly, the fibers orientation inside the specimens of fresh mortars was performed. Fig. 8 shows the actual image of the implemented equipment in order to generate the magnetic field capable of causing the desired effect. The molds used for the specimens RILEM $4 \times 4 \times 16 \mathrm{~cm}$ were designed in wood with the aim of having a non-ferromagnetic material. The magnetic field generated for fibers orientation was close to $500 \mathrm{mT}$, value experimentally tested that enables to orient a large number of fibers in the surface of the specimen and less in the center itself, as it is here where the

Table 7

$X$-ray diffraction analysis.

\begin{tabular}{lllll}
\hline \multirow{2}{*}{ Material } & \multicolumn{4}{l}{ Mineral relative abundance } \\
\cline { 2 - 5 } & Calcite & Phologotipe & Quartz & Sandine \\
\hline RA-Concrete & $* * * * * * *$ & $* *$ \\
\hline
\end{tabular}

mortar weight and the consistency of the pastry undermine this task.

Complementary tests were carried out in order to verify the correct orientation of fibres in the concrete matrix. Firstly, as shown in Fig. 9, a cuts were made in the sample in order to visualize the distribution of the fibres inside the samples and to check if indeed wanted distribution was carried out. In particular, in Fig. 9(b) shows homogenous distribution of metal fibres in all the transversal section of mortar, that corresponds to the central cut. On the other hand, Fig. 9(c) shows fibres orientation in longitudinal direction of the sample that corresponds to the direction of application of magnetic field created by the solenoid in order to improve mechanical properties of the material.

On the other hand, microscopy test through backscattered electrons was carried out as shown in Fig. 10. No cracks of big size were observed in the mortar matrix, only in some areas corresponding to recycled aggregates, so a good cohesion aggregate/cement can be assessed in this kind of mortars. In particular, Fig. 10(a) shows formation of ettringite needles what is characteristic for conglomerates made with cement due to the reaction of tricalcium aluminate with setting regulator [X]. Moreover, in samples elaborated with recycled aggregates, intergranular fracture is observed, in other words the material breaks at the edges of rounded grains. Fig. 10(b) shows the orientation of metal fibres inside mortar matrix improving mechanical properties of the material. All the fibres present the same orientation and are perfectly adhered to the binder.

In order to gage the inductive method and know both, fibers content and orientation, $100 \%$ of fiber content introduced during mixing in specimens within the solenoid was oriented. This enables to quantify the induction as shown in Fig. 11. The introduced fibers content was previously weighed based on the mixing percentages used to elaborate the specimens with recycled concrete aggregate.

Thus, measuring the differences in the coefficient of selfinduction, a relation between this variable and the amount of

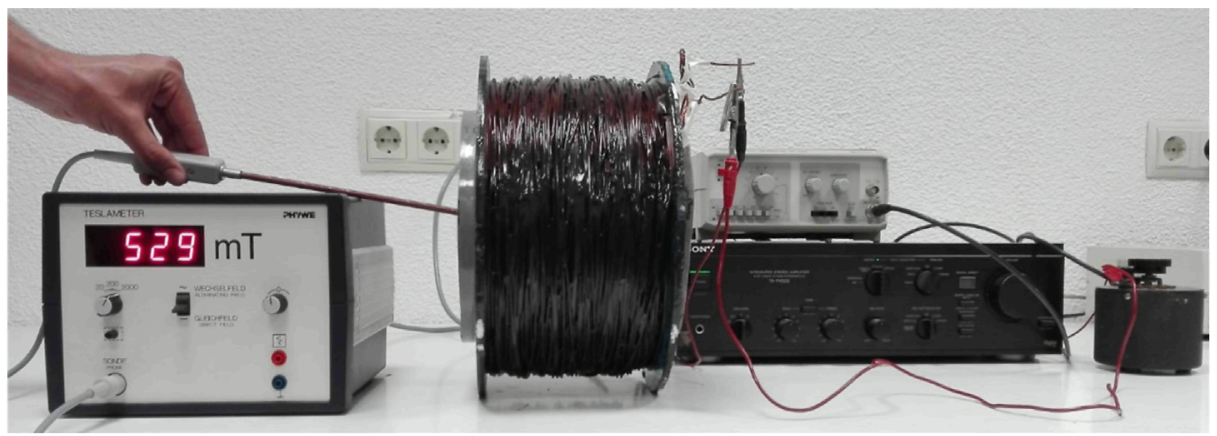

Fig. 8. Equipment designed to orient fibers in the mortar ma. 


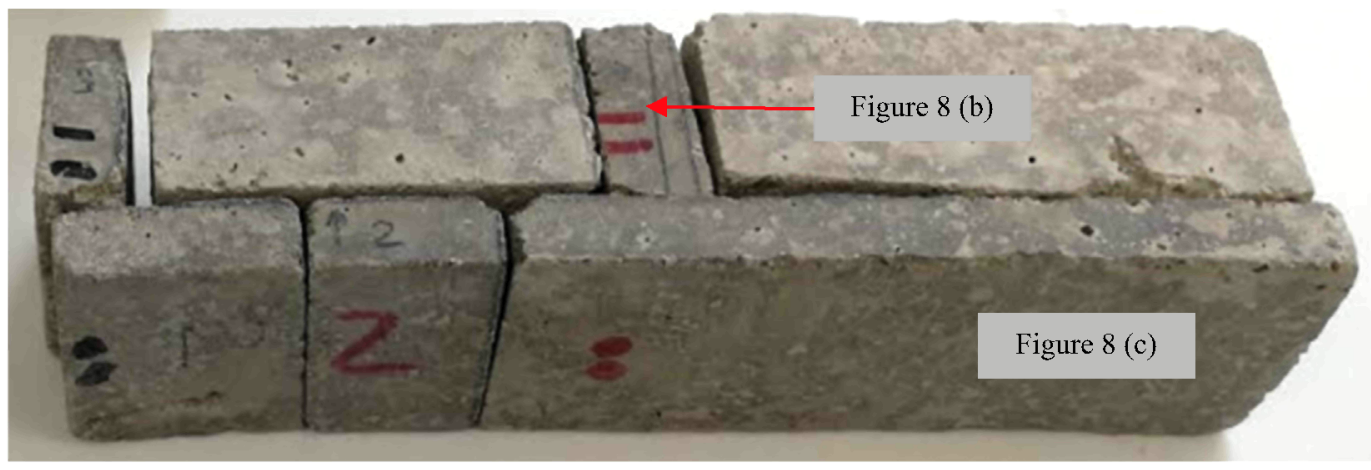

(a)

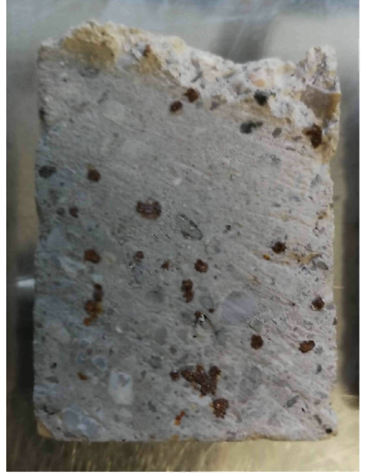

(b)

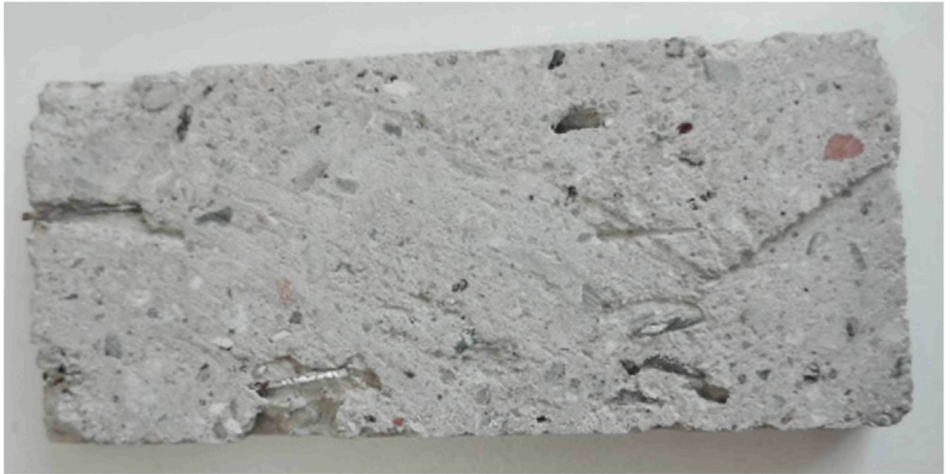

(c)

Fig. 9. (a) Oriented sample with cuts; (b) Transversal section with homogeneous distribution of steel fibres; (c) Longitudinal section with oriented steel fibres.

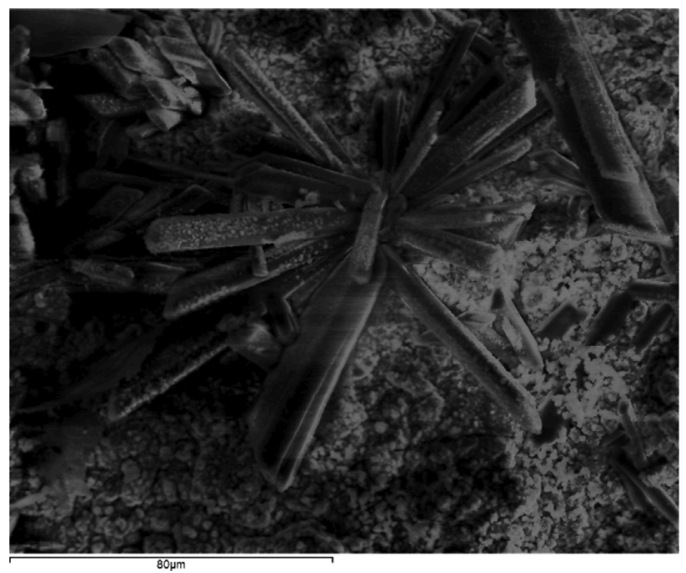

(a)

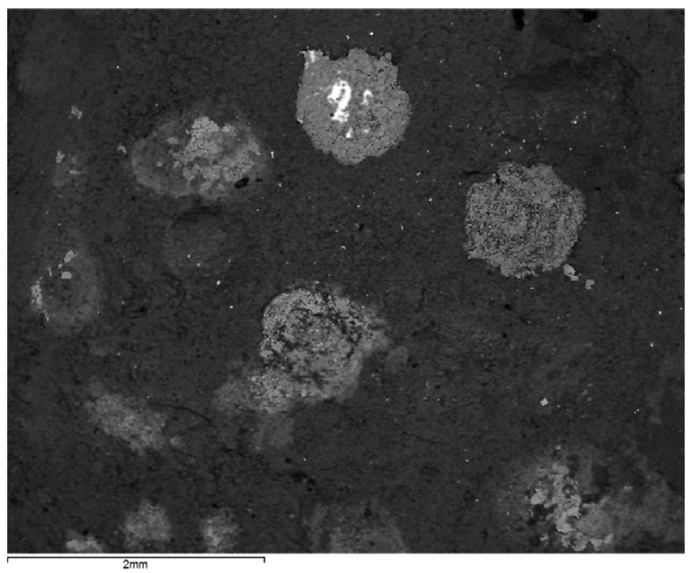

(b)

Fig. 10. (a) Ettringite crystals formed in the binder with $80 \mu \mathrm{m}$ definition; (b) Metal fibres oriented and adhered to mortar matrix with 2 mm definition.

oriented fibers can be obtained. As it can be observed in Fig. 11, when fibers are oriented in the longitudinal direction of the specimen parallel to the solenoid axis, the variation of the coefficient of self-induction increases with respect to the random fibers orientation. However, when they are oriented in transversal direction, this variation decreases, whatever their orientation is axis $\mathrm{Y}$ or axis $\mathrm{Z}$.

Once the induction produced by fibers orientation in the three directions of the space was known, it was possible to identify the percentage of oriented fibers within the mortar matrix by measuring this answer in the induction. The results of the orientation percentages for each type of mixing are displayed in Fig. 12.
As reported in Fig. 12, the solenoid designed as a method to orient fibers in the mortar matrix is validated. In both specimens elaborated with $0,5 \%$ and $1 \%$ of steel fiber, the prevailing orientation direction is the longitudinal that corresponds to the solenoid axis and to the direction in which the magnetic generated field is more intense. This let us orient fibers in transversal direction to the most unfavorable stress, that in this study, it is the flexural test.

\subsection{Mechanical tests}

Before mechanical tests, a characterization of mortars was carried out. It was analyzed their bulk density, their real density and 


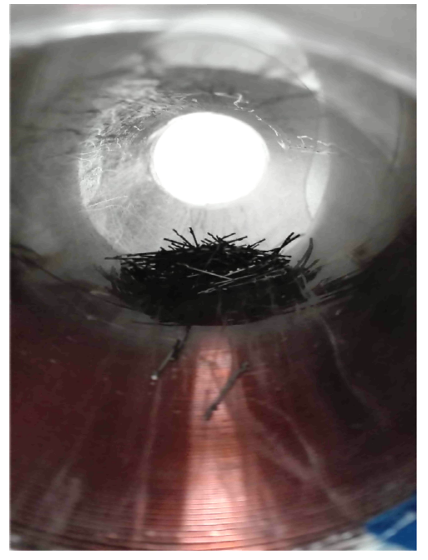

(a)

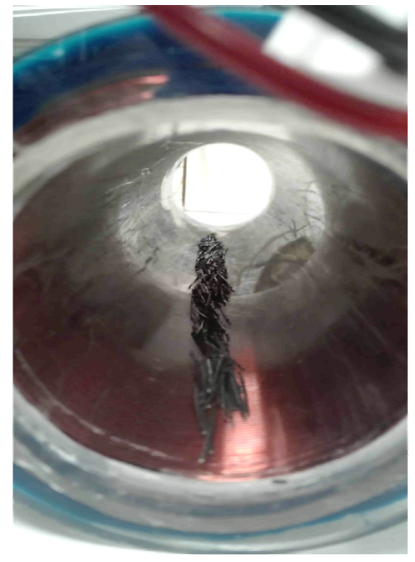

(b)

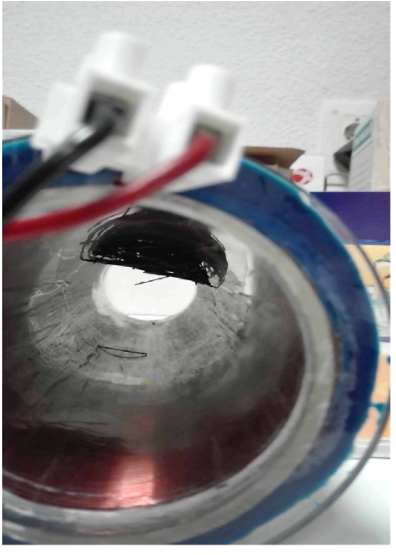

(c)

Fig. 11. 100\% Fibers orientation. (a) Random, (b) Longitudinal, (c) Transversal Z.

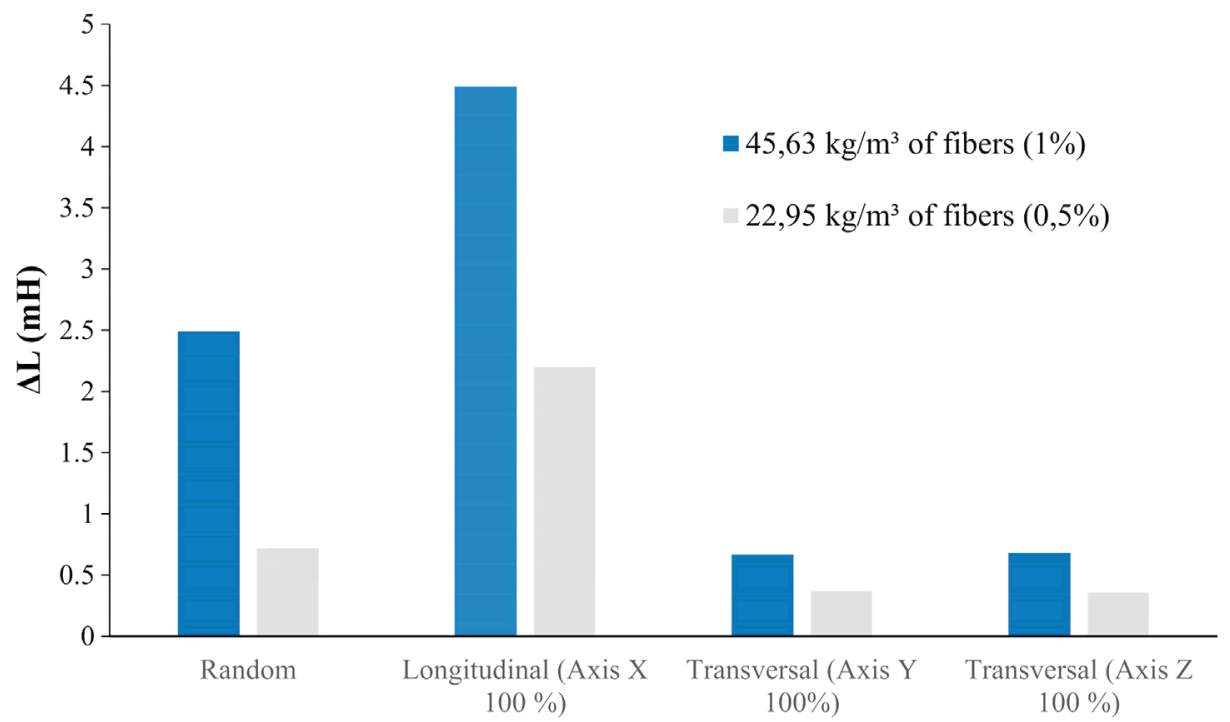

Fibers orientation

Fig. 12. Induction variation according to the direction of the oriented fibers within the specimen.

compacity due to their relationship in the mechanical behavior of the material (Table 8).

As Table 8 shows, the compacity and density of the mortars elaborated with NA is considerably higher to those elaborated with recycled concrete aggregate. This fact has an impact on the lower mechanical properties of the last mentioned mortars. The inclusion of steel fibers in percentages $0.5 \%$ and $1 \%$ does not increase significantly any of these properties.

Besides that, in Table 9, it can be seen how the inclusion of fibers increases substantially the flexural strength in the recycled mortars (with differences between the specimens with inclusion of oriented fibers and those without orientation). In dosage with

Table 8

Bulk density, real density and compacity of the mortars used in this study.

\begin{tabular}{|c|c|c|c|c|c|c|c|c|}
\hline \multirow[t]{2}{*}{ Test (without fibers) } & \multicolumn{4}{|c|}{$\mathrm{M}$ - NA } & \multicolumn{4}{|c|}{$\mathrm{M}-\mathrm{RA}$} \\
\hline & \multicolumn{2}{|l|}{$1: 3$} & \multicolumn{2}{|l|}{$1: 4$} & \multicolumn{2}{|l|}{$1: 3$} & \multicolumn{2}{|l|}{$1: 4$} \\
\hline Bulk Density $\left(\mathrm{g} / \mathrm{cm}^{3}\right)$ & \multicolumn{2}{|l|}{2,06} & \multicolumn{2}{|l|}{1,98} & \multicolumn{2}{|l|}{1,74} & \multicolumn{2}{|l|}{1,71} \\
\hline Real Density $\left(\mathrm{g} / \mathrm{cm}^{3}\right)$ & \multicolumn{2}{|l|}{2,32} & \multicolumn{2}{|l|}{2,27} & \multicolumn{2}{|l|}{2,22} & \multicolumn{2}{|l|}{2,27} \\
\hline Compacity (\%) & \multicolumn{2}{|l|}{88,79} & \multicolumn{2}{|l|}{87,22} & \multicolumn{2}{|l|}{78,38} & \multicolumn{2}{|l|}{75,33} \\
\hline \multirow[t]{2}{*}{ Test (with fibers) } & \multicolumn{2}{|c|}{$\mathrm{M}-\mathrm{RA}-\mathrm{SF}-0,5 \%$} & \multicolumn{2}{|c|}{$M-R A-S F-O-0,5 \%$} & \multicolumn{2}{|c|}{$M-R A-S F-1 \%$} & \multicolumn{2}{|c|}{$\mathrm{M}-\mathrm{RA}-\mathrm{SF}-\mathrm{O}-1 \%$} \\
\hline & $1: 3$ & $1: 4$ & $1: 3$ & $1: 4$ & $1: 3$ & $1: 4$ & $1: 3$ & $1: 4$ \\
\hline Bulk Density $\left(\mathrm{g} / \mathrm{cm}^{3}\right)$ & 1,75 & 1.72 & 1,76 & 1,72 & 1,77 & 1,72 & 1,78 & 1,70 \\
\hline Real Density $\left(\mathrm{g} / \mathrm{cm}^{3}\right)$ & 2,25 & 2,28 & 2,24 & 2,28 & 2,26 & 2,29 & 2.25 & 2,28 \\
\hline Compacity (\%) & 77,09 & 75,43 & 78,57 & 75,73 & 78,31 & 75,10 & 79,11 & 74,56 \\
\hline
\end{tabular}


Table 9

Flexural and compressive strengths.

\begin{tabular}{|c|c|c|c|c|c|c|c|c|}
\hline \multirow[t]{2}{*}{ Test (without fibers) } & \multicolumn{4}{|c|}{$\mathrm{M}$ - NA } & \multicolumn{4}{|c|}{$\mathrm{M}-\mathrm{RA}$} \\
\hline & \multicolumn{2}{|l|}{$1: 3$} & \multicolumn{2}{|l|}{$1: 4$} & \multicolumn{2}{|l|}{$1: 3$} & \multicolumn{2}{|l|}{$1: 4$} \\
\hline Flexural Strength (MPa) & \multicolumn{2}{|l|}{5,12} & \multicolumn{2}{|l|}{3,87} & \multicolumn{2}{|l|}{4,02} & \multicolumn{2}{|l|}{2,84} \\
\hline Compressive Strength (MPa) & \multicolumn{2}{|l|}{21,94} & \multicolumn{2}{|l|}{14,75} & \multicolumn{2}{|l|}{14,23} & \multicolumn{2}{|l|}{9,22} \\
\hline \multirow[t]{2}{*}{ Test (with fibers) } & \multicolumn{2}{|c|}{$M-R A-S F-0,5 \%$} & \multicolumn{2}{|c|}{$\begin{array}{l}\mathrm{M}-\mathrm{RA}-\mathrm{SF}-\mathrm{O}- \\
0,5 \%\end{array}$} & \multicolumn{2}{|c|}{$M-R A-S F-1 \%$} & \multicolumn{2}{|c|}{$\mathrm{M}-\mathrm{RA}-\mathrm{SF}-\mathrm{O}-1 \%$} \\
\hline & $1: 3$ & $1: 4$ & $1: 3$ & $1: 4$ & $1: 3$ & $1: 4$ & $1: 3$ & $1: 4$ \\
\hline Flexural Strength (MPa) & 4,25 & 2,94 & 4,50 & 3,15 & 4,45 & 3,03 & 4,84 & 3,29 \\
\hline Compressive Strength (MPa) & 14,34 & 9,29 & 14,75 & 9,47 & 14,71 & 9,78 & 15,14 & 9,97 \\
\hline
\end{tabular}

inclusion $1 \%$ in oriented steel fiber, the flexural strength increases around $17 \%$ in dosage $1: 3$ whereas in dosage $1: 4$ it is around $14 \%$. On the contrary, the compressive strength also improves although it is not significant as it does not exceed $6 \%$.

\subsection{Shrinkage}

Shrinkage is one of the main disadvantages of the RA mortars as they require higher amount of water for mixing elaboration due to

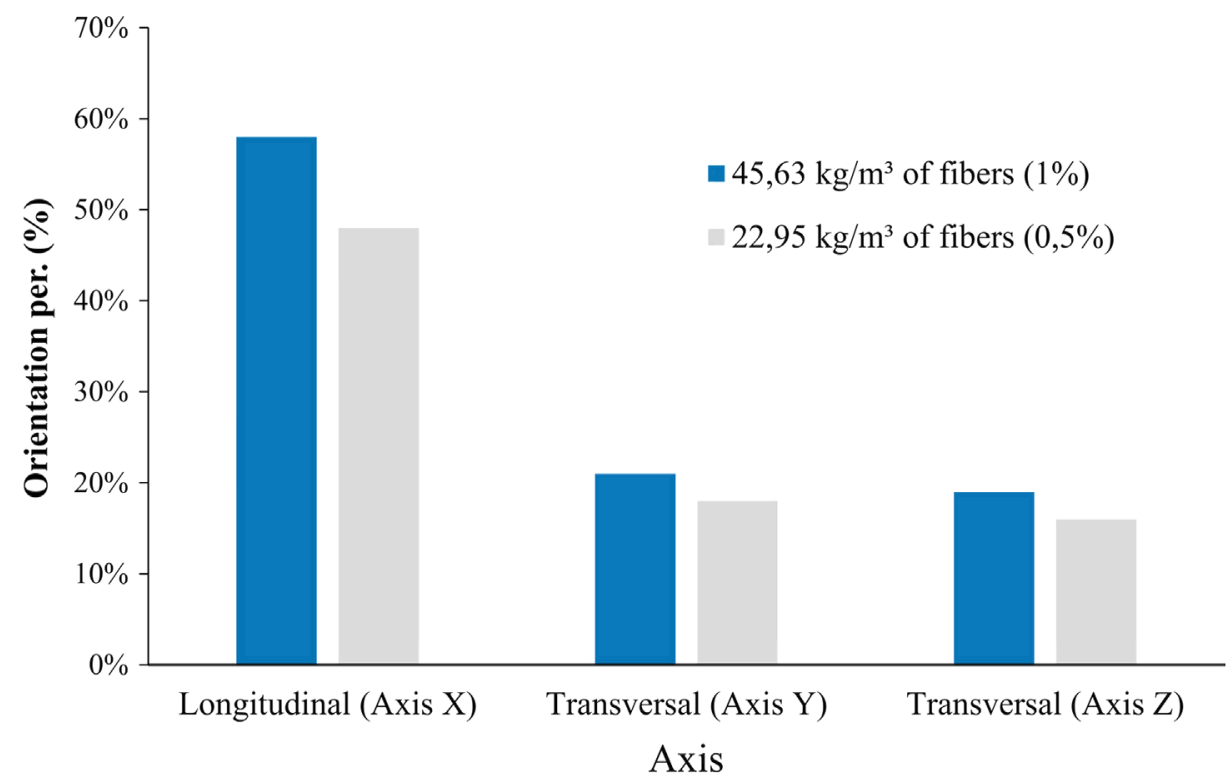

Fig. 13. Percentage of oriented fibers in the three directions of the space within each specimen.

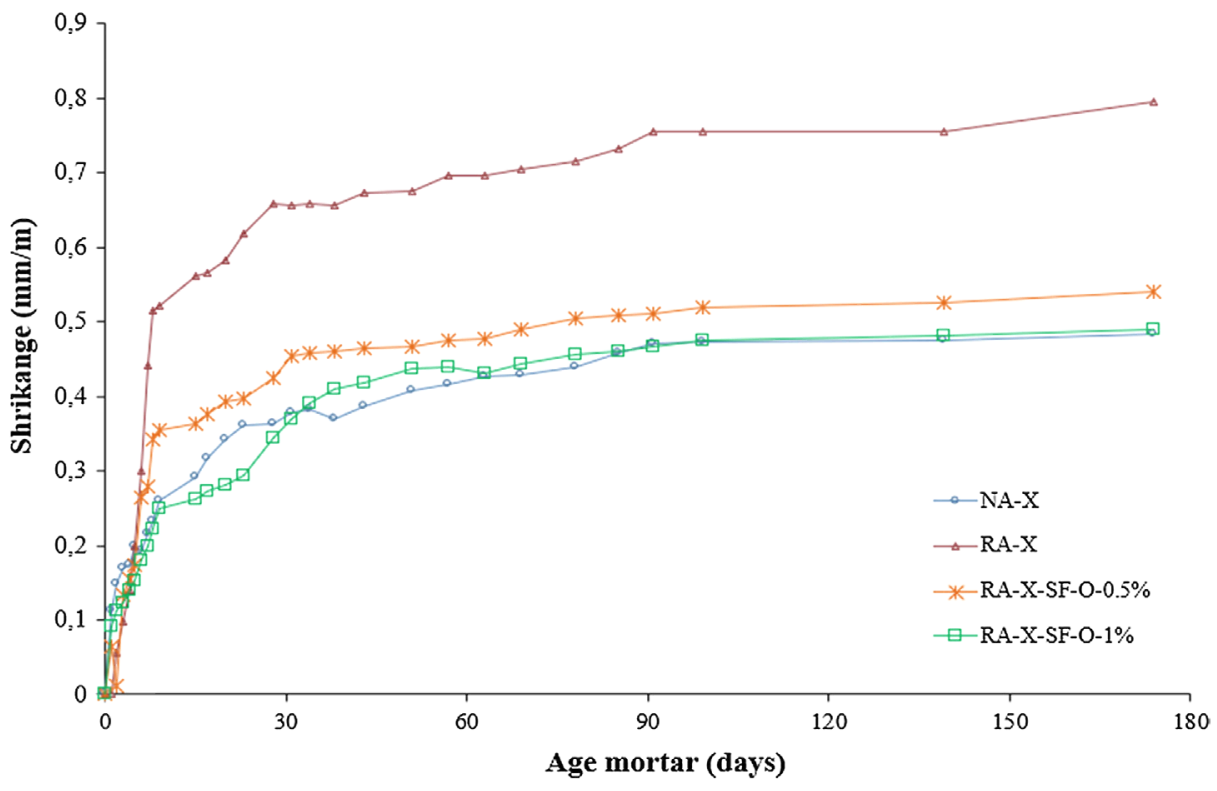

Fig. 14. Shrinkage test, dosage: $1: 3$. 


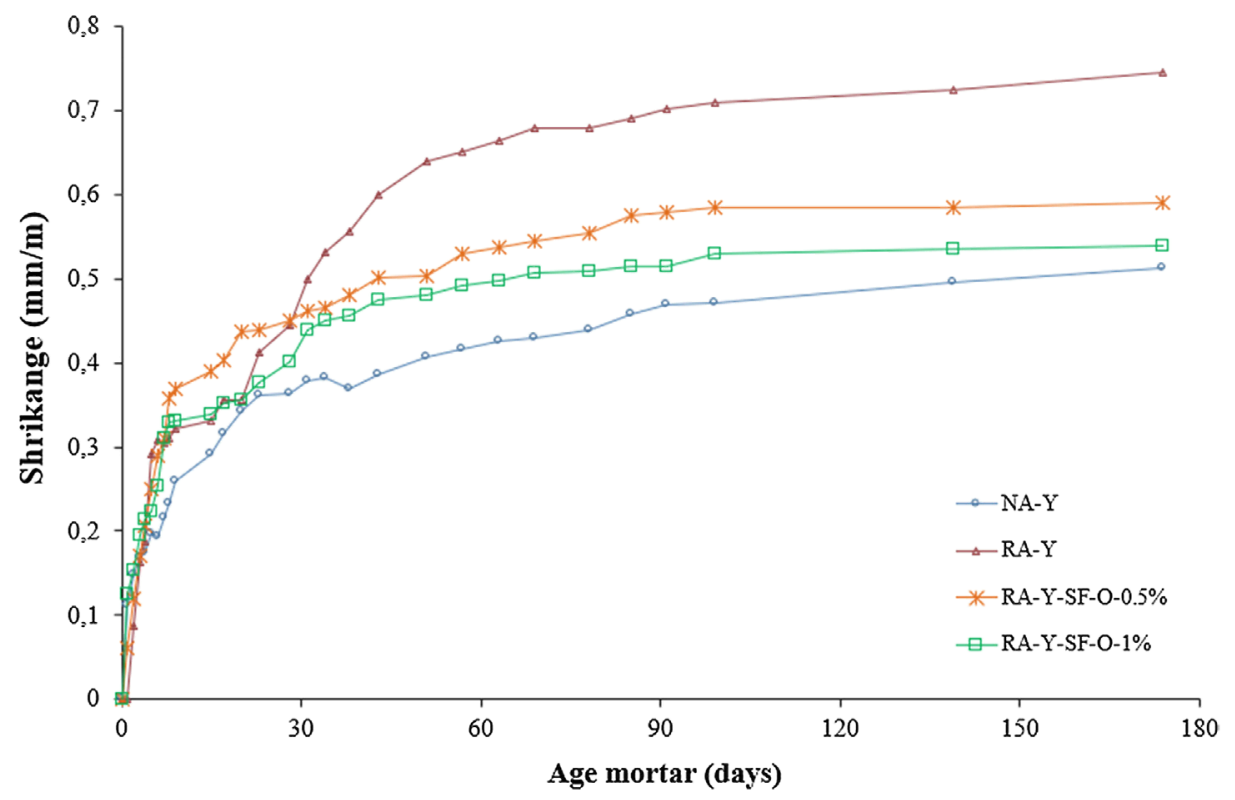

Fig. 15. Shrinkage test, dosage: 1:4.

their higher absorption. This can cause dimensional changes in the material. For this reason, the measurement period was 180 days and it could be observed that the adverse effect produced by this characteristic can be reduced with the inclusion of oriented steel fibers through the inductive method proposed in this study. Fig. 13 y 14, corresponding to 1:3 and 1:4 dosage, respectively.

As it can be seen in Figs. 14 and 15, the inclusion of steel fibers oriented in the RA mortars practically equals their shrinkage to the one provided by NA mortars. Shrinkage is reduced in a $38 \%$ in those specimens elaborated with 1:3 dosage and $1 \%$ of oriented steel fiber. Shrinkage will be reduced in a $28 \%$ in those specimens elaborated with 1:4 dosage in recycled concrete aggregate and $1 \%$ inclusion of steel fiber.

\section{Conclusions}

From the characterization of the recycled aggregate employed to mixing, some differences in comparison with NA were observed, that is, lower density and higher absorption. The recycled concrete aggregates provided by the company TEC-REC are mainly composed by silicates and show quartz and calcite are the main crystalline phases. Furthermore, their size distribution curve as well as the rest of their properties meet the requirements to be used as aggregates for the masonry mortar manufacturing.

Apart from this, it has been designed a solenoid capable of orienting the metallic fibers in the recycled mortars in order to improve their mechanical and shrinkage properties. The implemented equipment is able to generate a magnetic field of $500 \mathrm{mT}$ that has enabled the orientation of around $60 \%$ of fibers in the correct direction. It has also been designed a coil capable of verifying the orientation percentages in the three directions of the space. Thus, the implementation of the inductive method in this kind of materials is validated.

In relation to the properties of recycled mortars, the inclusion of steel fibers ameliorates both their mechanical strengths and shrinkage. These properties are usually penalized due to the characteristics of the RA. Results in mechanical testing show that fibers orientation in recycled mortars increases the flexural strength in around $10 \%$ with respect to the non-oriented mixing. However, the compressive strength does not show a significant improvement due to the orientation that does not correspond with the direction to the applied stress. Finally, the results obtained in the shrinkage study show how inclusion of steel fibers in $1 \%$ enables to reach similar values to those obtained in the traditional mortars at 178 days $(0.49 \mathrm{~mm} / \mathrm{m}$ for dosage $1: 3$ and $0.593 \mathrm{~mm} / \mathrm{m}$ for dosage $1: 4)$ reducing possible cracks and increasing the durability of this material.

\section{Declaration of Competing Interest}

None.

\section{Acknowledgements}

Authors express their gratitude to the Building Materials Lab in the Higher Technical School of Building Construction of Madrid and the services rendered in order to carry out this studio. Authors are also grateful to TEC-REC and Basf Company for the materials provided for this work.

\section{References}

[1] A. Bustos, A. Cobo, F. González, E. Moreno, Influence of fibers addittion on properties of hydraulic lime based mortars, DYNA 94 (2) (2018) 228-232, https:/dol.org/10.6036/8495.

[2] Boletín Oficial del Estado. (1895). Ley 16/1985, de 25 de junio, del Patrimonio Histórico Español. BOE-A-1985-12534.

[3] Eurostat, Environment and Energy, 2010. Generation and Treatment of Waste. Available in: http://ec.europa.eu/eurostat/.

[4] 1. Martínez, M. Etxeberria, E. Pavón, N. Díaz, A comparative analysis of the properties of recycled and natural aggregate in masonry mortars, Constr. Build. Mater. 49 (2013) 384-392, https://doi.org/10.1016/j.conbuildmat. 2013.08 .049 .

[5] M. Saiz, M. González, F. Fernández, A. Rodríguez, Comparative study of three types of fine recycled aggregates from construction and demolition waste (CDW) and their use in masonry mortar fabrication, J. Cleaner Prod. 118 (2016) 162-169, https://doi.org/10.1016/j.jclepro.2016.01.059.

[6] M. Martín, M. Zamorano, A. Ruiz-Moyano, I. Valverde, Characterization of recycled aggregates construction and demolition waste for concrete production following the Spanish Concrete Code EHE-08, Constr. Build. Mater. 25 (2011) 742-748, https://doi.org/10.1016/j.conbuildmat 2010.07.012

[7] Z. Hua Duan, C. Sun Poon, Properties of recycled aggregate concrete made with recycled aggregates with different amounts of old adhered mortars, Mater. Des. 58 (2014) 19-29, https://doi.org/10.1016/j.matdes.2014.01.044. 
[8] V. Corinaldesi, Environmentally-friendly bedding mortars for repair of historical buildings, Constr. Build. Mater. 35 (2012) 778-784, https://doi.org/ 10.1016/j.conbuildmat.2012.04.131.

[9] Spanish Ministry of Public Works. Instrucción de Hormigôn Estructural EHE-08 (Spanish Structural Concrete Code). BOE 2008; 203:258e66.

[10] A. Blanco, P. de la Pujadas, A. Fuente, S.H.P. Cavalaro, A. Aguado, Assessment of the fibre orientation factor in SFRC slabs, Compos. B 68 (2015) 343-354, https://doi.org/10.1016/j.compositesb.2014.09.001.

[11] C. Morón, P. Saiz, D. Ferrández, L. García-Fuentevilla, New system of shrinkage measurement through cement mortars drying, Sensors 17 (3) (2017) 522, https://doi.org/10.3390/s17030522.

[12] M. Sánchez de Juan, Estudio sobre la utilización de árido reciclado para la fabricación de hormigón estructural, E.T.S.I. Caminos, Canales y Puertos. Universidad Politécnica de Madrid, 2004. Tesis Doctoral.

[13] J.R. Jiménez, J. Ayuso, M. López, J.M. Fernández, J. De Brito, Use of fine recycled aggregates from a ceramic waste in masonry mortar manufacturing, Constr. Build. Mater. 40 (2013) 679-690, https:/doi.org/10.1016/j.conbuildmat. 2012.11.036.

[14] A. González, M. Etxeberria, Effects of using recycled aggregates on the shrinkage of high performance concrete, Constr. Build. Mater. 115 (2016) 32-41, https://doi.org/10.1016/j.conbuildmat.2016.04.031.

[15] M. Arce, S. Van García, N. den Bossche, Inspecciones en la gestión del agua de fachadas ventiladas basadas en la evaluación in situ y pruebas de laboratorio, Anales de Edificación 3 (1) (2017) 14-23, https://doi.org/10.20868/ ade.2017.3530.

[16] A. Bustos García, Morteros con propiedades mejoradas de ductilidad por adición de fibras de vidrio, carbono y basalto, Universidad Politécnica de Madrid E.T.S. de Edificación, 2018. Tesis Doctoral.

[17] J. Donnini, T. Bellezze, V. Corinaldesi, Mechanical, electrical and self-sensing properties of cementitious mortars containing short carbon fibers, J. Build. Eng. 20 (2018) 8-14, https://doi.org/10.1016/j.jobe.2018.06.011.

[18] H. Rodin, S. Nassiri, K. Englund, O. Fakron, H. Li, Recycled glass fiber reinforced polymer composites incorporated in mortar for improved mechanica performance, Constr. Build. Mater. 187 (2018) 738-751, https://doi.org/ 10.1016/j.conbuildmat.2018.07.169.

[19] R. Ralegaonkar, H. Gavali, P. Aswath, S. Abolmaali, Application of chopped basalt fibers in reinforced mortar: a review, Constr. Build. Mater. 164 (2018) 589-602, https://oi.org/10.1016/j.conbuildmat.2017.12.245.

[20] E.T. Dawood, M. Ramli, High strength characteristics of cement mortar reinforces with hybrid fibres, Constr. Build. Mater. 25 (2011) 2240-2247, https://doi.org/10.1016/j.conbuildmat.2010.11.008.

[21] P. Saiz, D. Ferrández, C. Morón, A. Payan, Comparative study of the influence of three types of fibre in the shrinkage of recycled mortar., Materiales de Construcción 68 (332) (2018) 1-2, https://doi.org/10.3989/mc.2018.07817.

[22] F. Laranjeira, Design Oriented Constitutive Model for Steel Fiber Reinforced Concrete, Tesis Doctoral de la Universidad Politécnica de Cataluña, 2010.

[23] H. Li, R. Mu, L. Qing, H. Chen, Y. Ma, The influence of fiber orientation on bleeding of steel fiber reinforced cementitious composites, Cem. Concr.
Compos. 92 (2018) 125-134, https://doi.org/10.1016/j.cemconcomp. 2018.05 .018$.

[24] M. Faifer, L. Ferrara, R. Ottoboni, S. Toscani, Low frequency electrical and magnetic methods for non-destructive analysis of fiber dispersion in fiber reinforced cementitious composites: an overview, Sensors 13 (2013) 13001318, https://doi.org/10.3390/s130101300.

[25] R. Mu, H. Li, L. Qing, J. Lin, Q. Zhao, Aligning steel fibers in cement mortar using electro-magnetic field, Constr. Build. Mater. 131 (2017) 309-316, https://doi. org/10.1016/j.conbuildmat.2016.11.081.

[26] P. Pujadas, A. Blanco, S.H.P. de la Cavalaro, A. Fuente, A. Aguado, Multidirectional double punch test to assess the post-cracking behaviour and fibre orientation of FRC, Constr. Build. Mater. 58 (2014) 214-224, https:// doi.org/10.1016/j.conbuildmat.2014.02.023.

[27] UNE-EN 197-1. (2001). Cement - Part 1: Composition, specifications and conformity criteria for common cements.

[28] Cement Permanent Commission. (2009). Instruction for the receipt of cement. RC-08. Ministry of Public Works and Transport.

[29] UNE-EN 196-1. (2005). Methods of testing cement - Part 1: Determination of strength.

[30] UNE-EN 1015-2. (1998). Methods of test for mortar for masonry - Part 2: Bulk sampling of mortars and preparation of test mortars.

[31] A. García, J.A. Carrasco, J.F. Soto, F. Maganto, C. Morón, A method for calculating the magnetic field produced by a coil of any shape, Sens. Actuators A 91 (2001) 230-232, https://doi.org/10.1016/S0924-4247(01), 00617-3.

[32] J.M. Torrents, A. Blanco, P. Pujadas, A. Aguado, P. Juan-Garcia, M.A. Sanchez, Inductive method for assessing the amount and orientation of steel fibers in concrete, Mater. Struct. 45 (2012) 1577-1592, https://doi.org/10.1617/ s11527-012-9858-6.

[33] UNE-EN 14721:2006+A1. (2008). métodos de ensayo para hormigón con fibras metálicas: determinación del contenido en fibras en el hormigón fresco y en el endurecido.

[34] UNE-EN 1015-11. (1999). Methods of test for mortar for masonry -Part 11: Determination of flexural and compressive strength of hardened mortar.

[35] UNE 80-112-89. (1989). Test methods. Cement. Determination of shrinkage and swelling in water.

[36] UNE-EN 13139. (2002). Aggregates for mortar.

[37] UNE-EN-933-1. (2012).Tests for geometrical properties of aggregates - Part 1: Determination of particle size distribution e Sieving method.

[38] UNE 83115. (1989). Aggregates for concrete. Determination of the coefficient of friability of the sands.

[39] UNE-EN 1097-3. (1999). Tests for mechanical and physical properties of aggregates. Part 3: determination of loose bulk density and voids.

[40] UNE-EN 1097-6. (2014). Tests for mechanical and physical properties of aggregates - Part 6: Determination of particle density and water absorption.

[41] Ministerio de Medio Ambiente y Medio Rural y Marino. (2015). Guía Española de Âridos Reciclados procedentes de Residuos de Construcción y Demolición (RCD). 